\title{
Implementasi CI/CD Pipeline Pada Framework Androbase Menggunakan Jenkins (Studi Kasus: PT. Andromedia)
}

\author{
Ahmad Farid ${ }^{1 *}$, Indra Gita Anugrah ${ }^{2}$ \\ 1,2 Universitas Muhammadiyah Gresik \\ Jl. Sumatera No.101, Kabupaten Gresik, Jawa Timur 61121 \\ Corresponding author's e-mail: ahmadfarid.gresik@gmail.com ${ }^{1}$, indragitaanugrah@umg.ac.id ${ }^{2}$
}

\begin{abstract}
Abstrak - Proses deployment dalam pembangunan sebuah aplikasi sangatlah penting karena menentukan hasil akhir sebuah aplikasi namun sayangnya proses ini kerapkali bermasalah dikarenakan cara deploy yang masih manual yaitu dengan cara pull aplikasi dari server produksi, cara ini dirasa kurang parktis dikarenakan developer harus berulangkali melakukan pull dari server apabila ada update pada aplikasi, masalah serupa terjadi pada sebuah perusahaan jasa system informasi PT.Andromedia dimana proses deploy yang dilakukan masih secara manual, berangkat dari permasalahan tersebut maka penulis menawarkan solusi dengan mengintegrasikan proses deploymen aplikasi dengan menggunakan konsep continuous integration and deployment atau yang biasa disingkat CI/CD. CI atau Continuous integration Merupakan prosses dimana aplikasi akan di buat dan di uji secara otomatis setelah repositori aplikasi terintegrasi pada server CI. Sedangkan $\mathrm{CD}$ atau Continuous deploymen adalah prosses dimana aplikasi yang telah dibuat dan di uji akan dideploy pada server produksi secara otomotis. dengan mengimplementasikan CI/CD dapat membantu dalam proses deployment.

Kata kunci: Deployment, Continuous Integration, Continuous deployment, Jenkins, Aplikasi
\end{abstract}

Abstrak - The deployment process in the development of an application is very important because it determines the final result of an application, but unfortunately this process is often problematic because the deployment method is still manual, namely by pulling the application from the production server, this method is considered less practical because the developer must repeatedly pull from the server if there is one. updating the application, a similar problem occurred in an information system service company PT. Andromedia where the deployment process was still done manually, departing from these problems, the author offered a solution by integrating the application deployment process using the concept of continuous integration and deployment or commonly abbreviated as CI. /CD. CI or Continuous integration Is a process where applications will be created and tested automatically after the application repository is integrated on the CI server. While CD or Continuous deployment is a process where applications that have been created and tested will be deployed on the production server automatically. implementing $\mathrm{CI} / \mathrm{CD}$ can help in the deployment process.

Keywords: Deployment, Continuous Integration, Continuous deployment, Jenkins, Application

\section{Pendahuluan}

Dalam proses pengembangan (development) sebuah aplikasi memiliki tahapan-tahapan yang harus dilakukan oleh pengembang aplikasi (developer) seperti analisis, design, develop dan release atau deploy. Deploy adalah tahap dimana aplikasi yang telah jadi akan dipublikasi atau disebar tergantung aplikasi yang dibuat. Dalam pengembangan sebuah aplikasi tahapan deploy adalah tahap yang sangat penting karena menentukan hasil akhir sebuah aplikasi, namun sayangnya tahapan ini kerap kali bermasalah, dikarenakan sistem yang masih bersifat manual. Cara yang dilakukan yaitu dengan memasukan aplikasi ke server kemudian developer menjalakan aplikasi tersebut. Apabila ada update pada aplikasi maka langkah tadi harus diulang. Sehingga menggunakan cara ini dirasa kurang efisien dan efektif karena developer harus deploy berulang kali apabila terdapat pengembangan pada aplikasi yang telah dibuat.

CI/CD merupakan salah satu dari bagian DevOps. DevOps sendiri merupakan salah satu praktik dalam proses pengembangan aplikasi dimana pada bagian development and Operations dilakukan secara otomatis dan dan saling terintegrasi, dengan menggunakan DevOps proses pengembangan aplikasi dapat dilakukan secara efektif dan efisien.

PT. Andromedia adalah sebuah perusahaan yang bergerak di bidang jasa system informasi. PT.Andromedia juga memiliki framework sendiri yang bernama androbase, yang digunakan untuk mempermudah proses development. Dalam proses development aplikasi pertama-tama para developer akan dibagikan fitur-fitur aplikasi yang akan dikerjakan pada computer masing-masing setelah fitur yang dikerjakan tidak ada masalah maka code disimpan pada tempat penyimpanan atau repository, setelah semua fitur yang dikerjakan selesai maka fitur-fitur tadi akan digabung atau merge sehinga menghasilkan aplikasi yang utuh, setelah itu aplikasi akan di test apabila tidak ada masalah maka aplikasi akan di deploy ke server, apabila setelah di deploy terdapat 
masalah maka para developer akan memperbaiki aplikasi dan melakukan deploy ulang secara manual, pada proses deploy ini dirasa kurang efektif karena para developer harus melakukan deploy manual secara teratur apabila ada masalah pada aplikasi.

Solusi yang dapat ditawarkan untuk permasalahan di atas adalah mengintegrasikan dengan sebuah sistem atau aplikasi yang dapat melakukan deploy dan sekaligus testing aplikasi yang dibuat secara otomatis apabila ada perubahan pada tempat penyimpanan atau repository aplikasi, dalam hal ini sistem atau aplikasi yang digunakan adalah jenkins. Jenkins sendiri merupakan aplikasi open-source yang digunakan untuk melakukan otomasi tugas-tugas di dalam proses continuous integration and delivery (CI/CD) sebuah aplikasi, solusi ini diharapkan dapat mempermudah developer PT. Andromedia dalam melakukan prosses deploy aplikasi.

\section{Tinjauan Pustaka}

\subsection{CI/CD Pipeline}

Continuous integration and deployment atau yang biasa disingkat $\mathrm{CI} / \mathrm{CD}$ merupakan prosses otomasi pada tahap testing dan deploy pada sebuah aplikasi dengan mengintegrasikan aplikasi pada layanan pihak ketiga, CI/CD dapat memastikan kode aplikasi selalu diuji, dan aman untuk di deploy. CI atau Continuous integration Merupakan prosses dimana aplikasi akan di buat dan di uji secara otomatis setelah repositorily aplikasi terintegrasi pada server CI. Sedangkan CD atau Continuous deployment adalah prosses dimana aplikasi yang telah dibuat dan di uji akan dideploy pada server produksi secara otomotis [1].

\subsection{Jenkins}

Jenkins adalah aplikasi open-source yang digunakan untuk melakukan otomasi tugas-tugas di dalam prosses continuous integration and delivery (CI/CD) sebuah aplikasi. Jenkins di pilih karena memiliki banyak fitur dan plugin yang mendukung semua repositori seperti Github, Gitlab, Bitbucket dan lainya [9].

\subsection{Framework}

Framework adalah sebuah kerangka kerja atau dasar dari suatu pembuatan aplikasi yang menyediakan fitur-fitur untuk mempermudah dan mempercepat prosses pembuatan aplikasi, dengan menggunakan framework para developer tidak lagi harus membuat aplikasi dari awal [15].

\subsection{Androbase}

Androbase adalah framework yang dibuat oleh PT. Andromedia untuk mempermudah para developernya dalam mendevelop aplikasi, Androbase sendiri dibuat dengan menggunakan javascript sebagai Bahasa pemrogramannya, react js untuk frontend dan prisma js untuk object relational model (ORM).

\subsection{Git}

Git merupakan version control yang digunakan untuk memelihara versi dari code, sehinga setiap developer dapat membuat branch mereka masing-masing, git juga dapat dikombinasikan dengan git repository yang dapat memudahkan para developer berkolaborasi dan memenejemen code [3][8].

\section{Metode Penelitian}

Dalam metode penelitian ini memiliki tahapan-tahapan yang dibuat dalam acuan dalam pembuatan penelitian. Tahapan pertama adalah identifikasi masalah, pada tahapan ini penulis mengidentifikasi masalah pada development aplikasi di PT. Andromedia dimana pada saat development aplikasi masih menggunakan cara manual. Tahapan kedua adalah rumusan masalah dimana pada tahapan ini penulis mengajukan solusi dengan menggunakan CI/CD Pipeline yang dapat di lihat dalam gambar berikut.

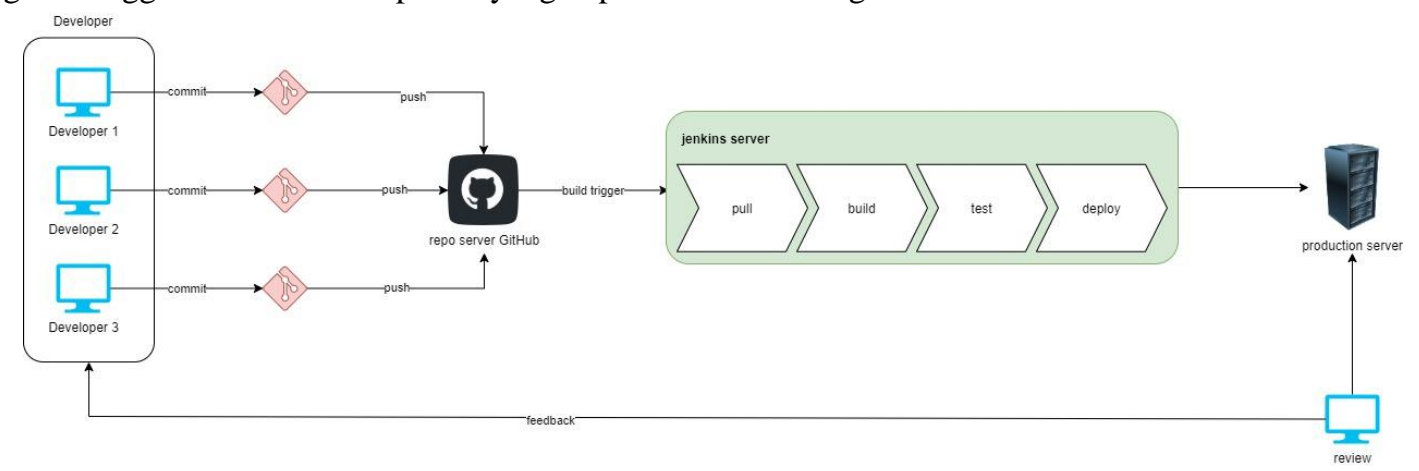

Gambar 1. Alur CI/CD pipeline

Tahapan selanjutnya adalah mengimplementasikan CI/CD Pipeline dengan menggunakan jenkins, Dan untuk tahapa terakhir adalah pengujian dan hasil kesimpulan dimana aplikasi yang telah terintegrasi dengan jenkins 
akan di uji dan dari hasil pengujian tersebut dapat di Tarik hasil kesimpulan.

\section{Hasil dan Pembahasan}

Penelitian ini di awali dengan melakukan installasi git pada computer masing-masing developer dan jenkins pada server lokal, setelah aplikasi yang di butuhkan terinstall maka langkah selanjutnya adalah membuat repository baru di github kemudian framework androbase di masukan (push) ke repository tersebut, repository yang dibuat dapat dilihat pada gambar berikut.

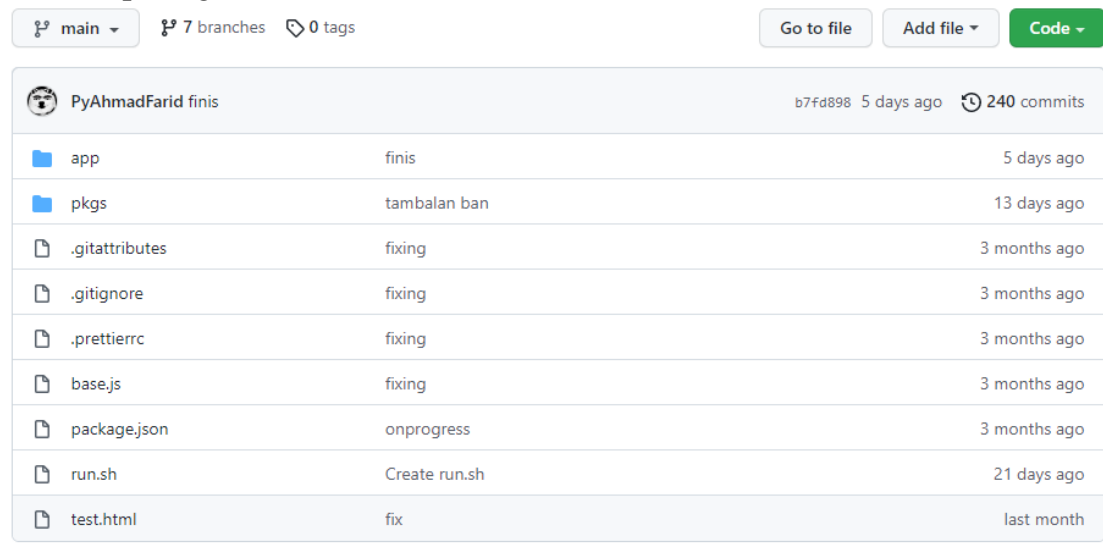

Gambar 2. Repositori GitHub

Untuk langkah berikutnya adalah membuat job pipeline pada jenkins yang kemudian job tersebut diintegrasikan dengan repository github yang telah dibuat, Setelah job terintegrasi dengan github maka langkah selanjutnya adalah mendefinisikan stage stage yang akan di eksekusi apabila terdapat perubahan pada repository github stage stage yang dibuat dapat dilihat pada gambar berikut

\section{Stage View}

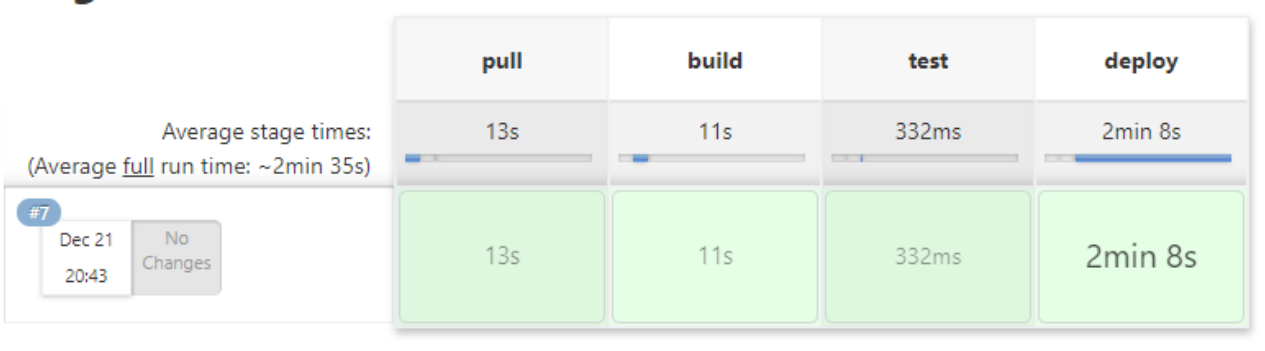

Gambar 3. Stage success

Pada gambar 3 dapat di lihat pipeline memiliki 4 stage yang di eksekusi secara berurutan,

1.Stage Pull

Stage pertama adalah stage pull dimana jenkins akan mengambil aplikasi dari repository github (pull) yang kemudian disimpan ke directory lokal.

2. Stage Build

Stage ke dua adalah stage build dimana pada stage ini aplikasi yang telah di pull akan dibangun (build) sehingga menghasilkan aplikasi yang seutuhnya.

3. Stage Test

stage selanjutnya adalah stage test dimana pada stage ini aplikasi akan di uji apabila pada stage ini tidak terdapat masalah atau error maka aplikasi akan masuk ke selanjutnya.

4. Stage Deploy

Stage terakhir adalah stage deploy dimana aplikasi akan di deploy ke server produksi. Apabila terdapat error pada salah satu stage maka stage berikutnya tidak akan di jalankan sehingga hal ini dapat mencegah deployment aplikasi yang terdapat masalah. 


\section{Stage View}

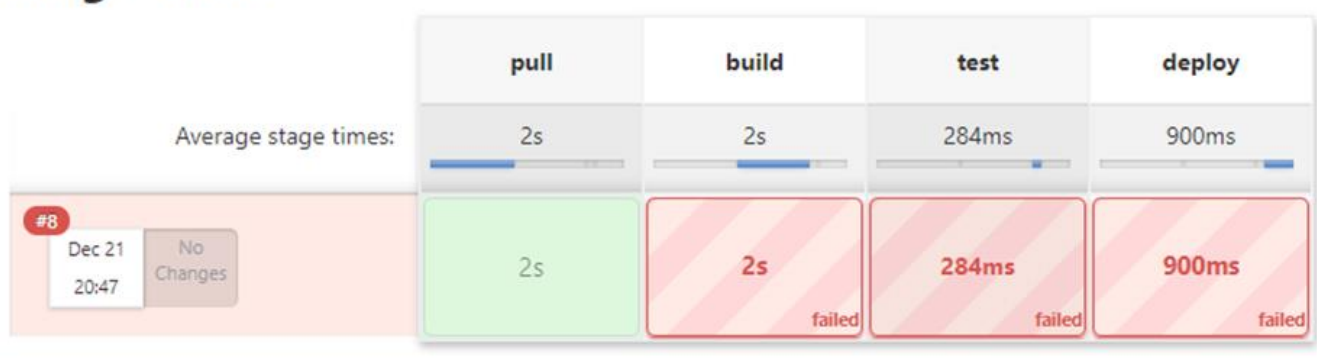

Gambar 4. Stage failed

Pada gambar 4 dapat dilihat saat stage build terdapat masalah maka stage test dan stage deploy tidak tereksekusi, untuk log dari pipline Jenkins dapat dilihat pada gambar berikut.

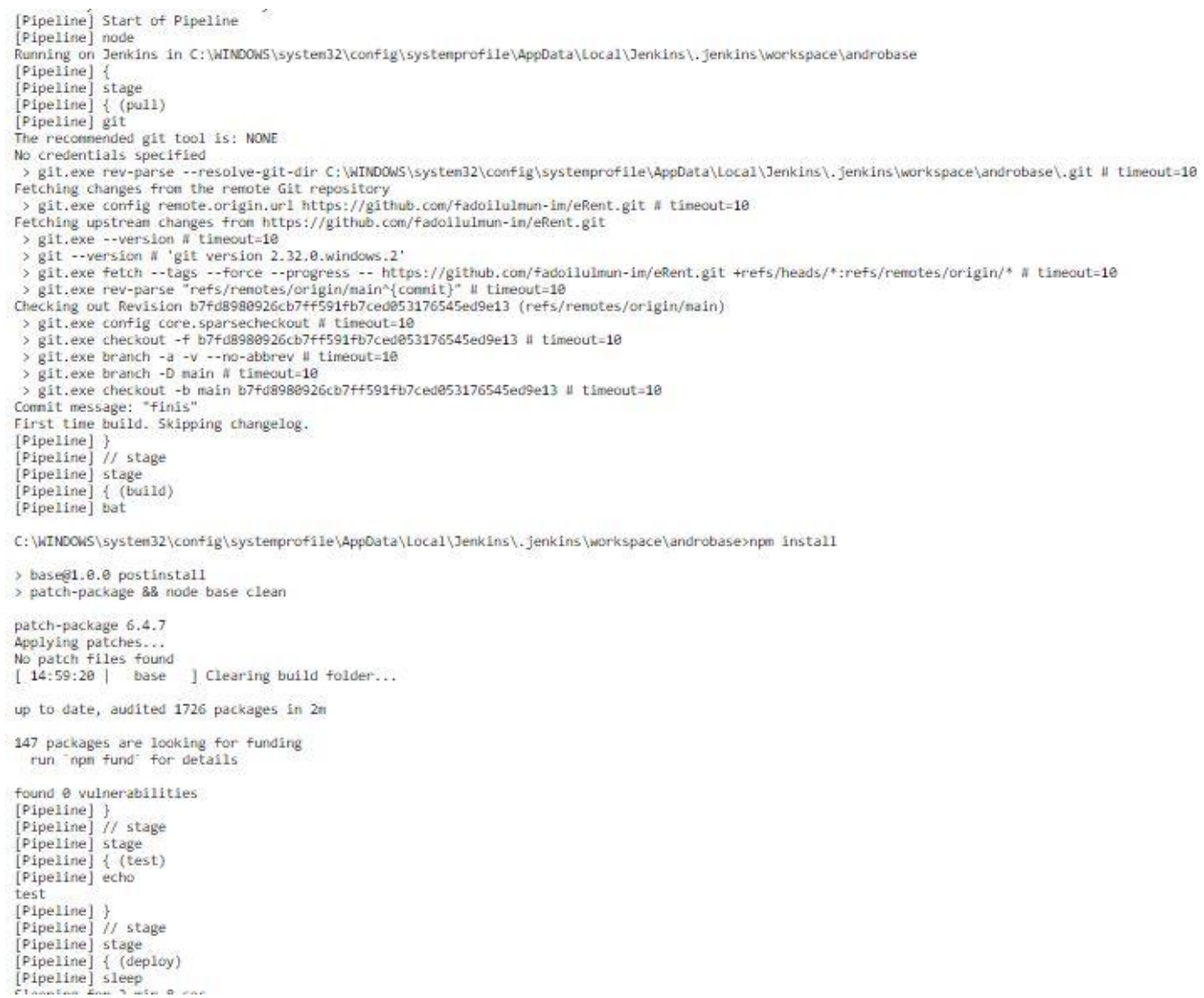

Gambar 5. Log Jenkins

Pada penelitian ini aplikasi yang di deploy adalah contoh aplikasi yang dibangun dengan menggunakan framework androbase. Berikut adalah tampila framework androbase yang sukses di deploy menggunakan jenkins. 


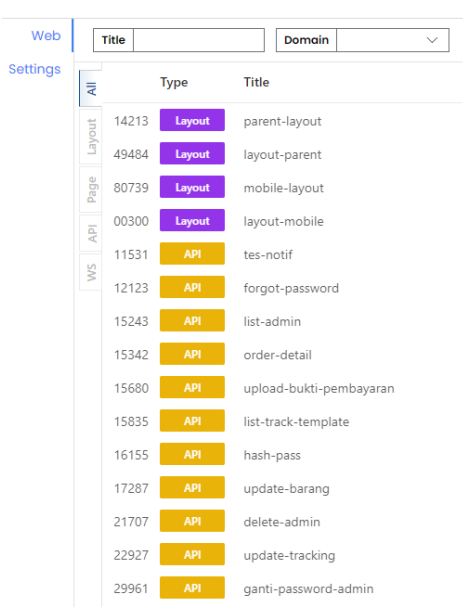

Gambar 6. Androbase

Dengan mengintegrasikan aplikasi androbase dengan CI/CD pipeline dapat mempermudah proses deployment aplikasi pada PT. Andromedia yang mana pada sistem sebelumnya masih menggunakan cara manual namun dengan menggunakan CI/CD proses deployment menjadi lebih cepat dan otomatis, untuk hasil pengujian $\mathrm{CI} / \mathrm{CD}$ penulis melakukan perbandingan antara system $\mathrm{CI} / \mathrm{CD}$ dengan system manual, hasil berbandingan dapat dilihat pada table berikut

\begin{tabular}{|l|l|l|}
\hline No & Sebelum & Sesudah \\
\hline 1 & $\begin{array}{l}\text { Proses deploy mengunakan cara } \\
\text { manual dengan memasukan aplikasi ke } \\
\text { server secara langsung. }\end{array}$ & $\begin{array}{l}\text { Proses deploy mengunakan cara otomatis } \\
\text { dengan mengunakan jenkins. }\end{array}$ \\
\hline 2 & $\begin{array}{l}\text { Update aplikasi produksi dilakukan } \\
\text { secara rutin. }\end{array}$ & $\begin{array}{l}\text { Update aplikasi produksi dilakukan apabila } \\
\text { terdapat update pada repository. }\end{array}$ \\
\hline 3 & Testing secara manual. & Testing dilakukan secara otomatis. \\
\hline
\end{tabular}

Tabel 1. Pengujian

\section{Kesimpulan}

Dari hasil penelitian dapat disimpulkan bahwa dengan menerapkan sistem CI/CD pipeline dengan menggunakan aplikasi jenkins dapat mempermudah proses deploymen aplikasi dimana proses deployment yang awalnya menggunakan cara manual dengan CI/CD dapat dilakukan secara otomatis cara ini juga dapat menghemat waktu dan juga dapat meminimalisir kesalahan. Dengan menggunakan sistem ini semoga dapat membantu developer PT.Andromedia dalam mendevelop aplikasi.

\section{Daftar Pustaka}

[1] Indra Guna Noviantama and Ari Purno Wahyu W, "IMPLEMENTASI CONTIONOUS INTEGRATION DAN CONTINOUS DEPLOYMENT PADA APLIKASI LEARNING MANAGEMENT SYSTEM DI PT. MILLENNIA SOLUSI INFORMATIKA," Jurnal Ilmiah Teknologi Informasi Terapan, vol 8, no 1, 2021.

[2] Fileni Zalukhu and Veri Arinal, "IMPLEMENTASI SISTEM PERSEDIAAN BARANG BERBASIS WEB DENGAN METODE DevOps PADA PT. HEINZ ABC INDONESIA," SOSTECH (Jurnal Sosial dan Teknologi), vol 1, no 1, 2021.

[3] Danur Wijayanto, Arizona Firdonsyah and Faisal Dharma Adhinata, "Implementasi Continous Integration/Continous Delivery Menggunakan Process Manager 2 (Studi Kasus: SIAKAD Akademi Keperawatan Bina Insan)," TEKNIKA, vol 10, no 3, 2021.

[4] Umi Sa'adah, et al., "FRAMEWORK TESTING OTOMATIS BERBASIS SERENITY DAN JENKINS AUTOMATED BUILD," JUTI (Jurnal Ilmiah Teknologi Informasi), vol 19, no 2, 2021. 
[5] Rendy Wijaya, Andri Prasetyo and Dian Wahyuningsih, "IMPLEMENTASI CI/CD UNTUK BUIDDAN DEPLOY WEBSITE DENGAN DOCKER RUNNER PADA ORGANISASI BELAJAR LINUX ID," SeNTIK (Seminar Nasional Teknologi Informasi dan Komunikasi), 2021.

[6] Sendy Ferdian, et al., "Continuous Integration and Continuous Delivery Platform Development of Software Engineering and Software Project Management in Higher Education," JuTISI (Jurnal Teknik Informatika dan Sistem Informasi), vol 7, no 1, 2021.

[7] Abriza Mahandis Shama and Dian W. Chandra, "Implementasi Static Application Security Testing Menggunakan Jenkins CI/CD Berbasis Docker Container Pada PT. Emporia Digital Raya," Jurnal Ilmiah Informatika (JIF), vol 9, no 2, 2021.

[8] Rahmad Ade Putra, "ANALISA IMPLEMENTASI ARSITEKTUR MICROSERVICES BERBASIS KONTAINER PADA KOMUNITAS PENGEMBANG PERANGKAT LUNAK SUMBER TERBUKA (OPENDAYLIGHT DEVOPS COMMUNITY)," Jurnal Sistem Informasi, Teknologi Informasi dan Komputer, vol 9, no 2.

[9] Jaga My Priera and Robi Tanzil Ganefi, "AUTOMATIC DEPLOYMENT SYSTEM DENGAN MENGGUNAKAN METODE CONTINUOUS INTEGRATION DI KAKATU,”Jurnal Ilmiah Komputer dan Informatika.

[10] Andrian Alpery and Muhammad Arif Fadhly Ridha, "IMPLEMENTASI CI/CD DALAM PENGEMBANGAN APLIKASI WEB MENGGUNAKAN DOCKER DAN JENKINS," 9th Applied Business and Engineering Conference, 2021.

[11] Tohirin, et al., "Implementasi DevOps pada Pengembangan Aplikasi e-Skrining Covid-1," JURNAL MULTINETICS, vol 6, no 1, 2020.

[12] Fransiskus Andika Setiawan, et al., "PENGUJIAN PROYEK WEBSITE OTOMATISASI DENGAN PENDEKATAN INTEGRASI ANTARA SELENIUM DAN TESTNG PADA ENVIROMENT JENKINS," pp. 1-14, 2015.

[13] Syafrial fachri pane, et al., "Implementasi Middleware Pada Evomo Dengan Metode Web Service Restfull Dan Pengujian CI/CD, Coverage Serta Simulasi Protokol Grafana," Jurnal Tekno Insentif, vol 15, no 2, 2021.

[14] Wahyuni Puji Lestari and Ari Sujarwo, "DevOps: Disrupsi pengelolaan ICT pendidikan tinggi," SNATI, 2018.

[15] Mara Destiningrum and Qadhli Jafar Adrian, "SISTEM INFORMASI PENJADWALAN DOKTER BERBASSIS WEB DENGAN MENGGUNAKAN FRAMEWORK CODEIGNITER (STUDI KASUS: RUMAH SAKIT YUKUM MEDICAL CENTRE),” Jurnal TEKNOINFO, vol 10, no 2, 2017. 